TALIM: JOURNAL OF EDUCATION IN MUSLIM SOCIETIES AND COMMUNITIES

Kabul: 09.01.2021

Copyright@2020 • ÖNDER

OnlineFirst: 21.01 .2021

https://dergipark.org.tr/en/pub/talim

DOI: http://dx.doi.org/10.37344/talim.2021.13

e-ISSN 2630-5887

Aralık $2020 \cdot 5(3) \cdot 45-54$

\title{
Türkiye’nin Eğitimde Modernleşme Süreci Aralığından Bozkırdaki Çekirdek Romanına Bakış: \\ Köy Enstitüleri
}

Süleyman Dulkar ${ }^{1}$, Akın Tek $^{2}$

$\ddot{O} z$

Eğitim, hayatımızda önemli bir meseledir. Özellikle Rönesans ve Reform süreçleriyle farklı boyutlara ve şekillere bürünmeye başlayan eğitim sürecimiz, günümüzde çözümü aranmaya devam eden sancılar arasındadır. Özellikle II. Abdülhamit döneminde modern okulların altyapısının hazırlanmasıyla günümüz modern eğitim sistemine adım atılmış oldu. Bu çalışmada, Cumhuriyet Dönemi'nde temelleri atılan modern okulların ilklerinden olan Köy Enstitüleri, Kemal Tahir'in Bozkırdaki Çekirdek romanıyla incelenecektir. Köy Enstitüleri, Tanzimat'tan Cumhuriyet'e kadar modernleşme sürecinin aktarılmasının ardından amaç, süreç ve nitelik bağlamında değerlendirilecektir. En son ise Kemal Tahir'in Köy Enstitülerine karşı eğitim felsefesi yönünden eleştirel bakışı, romandan örneklerle özellikle Şefik Ertem karakteri gözüyle ele alınacaktır.

\section{Anahtar kelimeler}

Kemal Tahir, Bozkırdaki Çekirdek, Eğitim, Tanzimat, Cumhuriyet, Modernleşme, Eğitim Felsefesi, Köy, Köy Enstitüleri

1 Yetkilendirilmiş yazar: Marmara Üniversitesi, Siyasal Bilgiler Fakültesi, İstanbul, Türkiye, dulkarsuleyman@gmail.com, ORCID ID: 0000-0001-5187-6289

2 İstanbul Şehir Üniversitesi, akintek@sehir.edu.tr, ORCID ID: 0000-0001-8884-9313 


\title{
A View to the Novel "Bozkırdaki Çekirdek" from the Perspective of Turkey's Modernization Process in Education: Village Institutes
}

\author{
Süleyman Dulkar, Akın Tek
}

\begin{abstract}
Education is an important issue in our life. Our education process, which started to take on different dimensions and shapes especially with the Renaissance and Reform processes, is among the pains that continue to seek solutions today. Especially with the establishment of modern schools during the Abdulhamid II period, the first step was taken in today's modern education system. In this study, Village Institutes, which is one of the first modern schools established in the Republic Period, will be examined with Kemal Tahir's novel Bozkırdaki Çekirdek. After explaining the modernization process from Tanzimat to the Republic, Village Institutes will be evaluated in terms of purpose, process and quality. Finally, Kemal Tahir's critical approach towards the Village Institutes in terms of educational philosophy will be discussed with examples from the novel, especially the character of Şefik Ertem.
\end{abstract}

\section{Keywords}

Kemal Tahir, Bozkırdaki Çekirdek, Education, Tanzimat, Republic, Modernization, Philosophy of Education, Village, Village Institutes

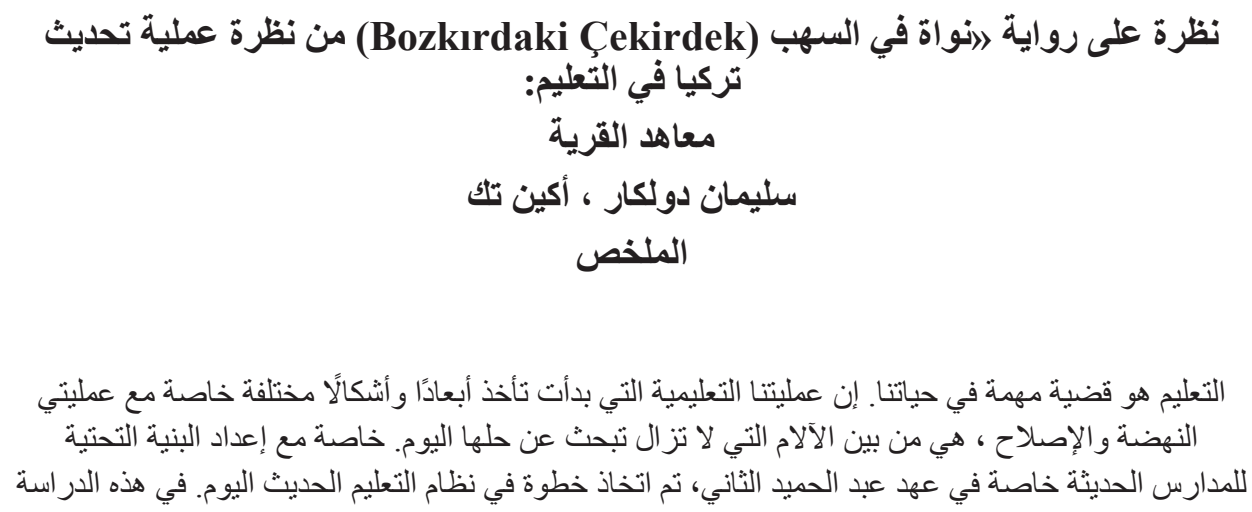




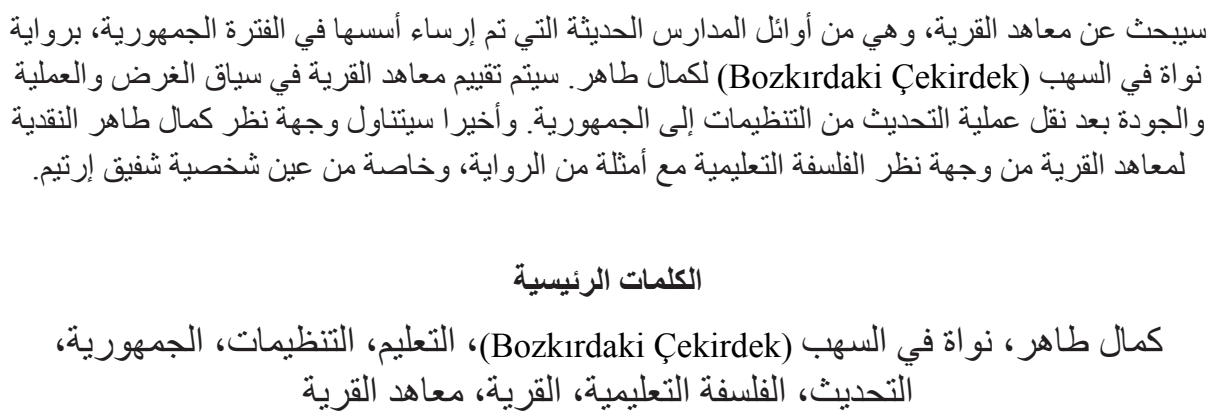

Giriş

Eğitim, önemli bir evrensel kavram olarak her gün her an insanların karşısına çıkar. Öğrenme eğilimi insanların tabiatındaki durumlardan biri olarak onların yaşantılarına şekil verir, onları değiştirir, kötüleştirir veya iyileştirir. Bu sebepledir ki öğretmenlerden talebelere, psikologlardan siyasetçilere, çiftçilerden herhangi bir zanaat dalına kadar insana dokunan bir olgudur. Dünyada bu eğitim/öğretim meselesinin genel itibariyle "her an öğrenme" anlamının yanı sıra belirli bir çerçeve içerisinde ve belirlenen bir topluluğa göre okullar vesilesiyle verilen bir biçiminin olduğu, bunun ülkelere ve kültürlere göre farkl1lıklar gösterdiği, bazı zaman dilimlerinde değişen dünya ile şeklinin yenilenmesinin icap ettiği basitçe ifade edilebilir. Nitekim modernizmin dünyada eğitime dayattığ değişim ise bu biçim (eğitim) yeniliğinin gerekliliği anlamında ortaya çıkar. Türkiye'de de bu mesele özellikle köydeki eğitimin ilerlemesi çalışmalarında derin izler bırakan sonuçlar doğurmuştur. Kemal Tahir'in Bozkırdaki Çekirdek romanı bu izleri farklı yönleriyle, farklı görüşler çerçevesinde Köy Enstitüleri özelinde inceleyen bir eserdir. Bu çalışmada, Tanzimat'tan erken Cumhuriyet tarihine kadar uzanan zaman diliminde eğitimin modernleşme sürecine tarihsel olarak değinilecek ve sonrasında Cumhuriyet Dönemi'nin eğitim politikaları dikkate alınarak bu politikaların ürünlerinden biri olan Köy Enstitüleri amaç, süreç ve nitelik düzleminde incelenecektir. Son olarak ise Kemal Tahir'in Bozkırdaki Çekirdek adlı romanında Köy Enstitülerine karşı eleştirel bakışı, romandan örneklerle özellikle Şefik Ertem karakteri doğrultusunda incelenecektir.

\section{Tanzimat'tan Erken Cumhuriyet'e Eğitimde Modernleşme Süreci}

Bilindiği üzere modernizm kavramı, Batı'daki Rönesans ve Reform, bilim alanındaki gelişmeler, sanayi devrimi ve siyaset alanındaki gelişmelerin Aydınlanma Çağı diye adlandırılan dönemle bütünleşip ortaya çıkan modernite kavramının tüm dünyaya yayılması durumudur (Beriş, 2003, s.485-496). Bu kavram ve getirilerinden dünya hiç şüphesiz çok etkilendi. Bundan nasibini alanlardan biri ise Osmanlı Devleti'ydi. $\mathrm{Bu}$ gelişmelerin ve düşüncelerin ticarette, siyasette, üretimde somut olarak yansıması 
ve devletleri çevrelemesi Osmanlı'nın da bu sürece yavaş yavaş ve özellikle belirli alanlarda dahil olmasını sağladı. Bu alanlardan birisi ise eğitimdi. "Modernleşme sürecini başlatan toplumlar, bu nedenle öncelikle mevcut eğitim sistemini revize etmeye ve öne çıkan engelleri tespit etmeye çalışmışlardır. Bu çaba, zamanla devletlerin temel politikalarından biri haline gelmiş ve devletin varlığının, eğitim-öğretim sürecinde ihtiyaç duyulan yetilerle donatılan bireyler sayesinde korunacağı temel varsayımlar arasında yer almıştır.” (Bozaslan ve Çokoğullar, 2015, s.311). açıklamaları eğitimdeki ilk çabaları ortaya koyuyor. Eğitimde modernleşme çalışmaları ilk olarak askeri okullarda başladı ve sorun ilk burada arandı zira Osmanlı'nın toprak kayıpları -teknik ve eğitimsel eksikliklerden kaynaklanan- yenilgileri dolayısıyla artıyordu. $\mathrm{Bu}$ anlamda Şen'in (2013, s.481) “Özellikle 17. yüzyıldan sonra askeri alanda yenilgilerin artmasıyla Osmanlı kendini sorgulamaya ve çareler aramaya başladı. Bundan dolayı da askeri bozulmaları tespit etmeye çalışıp askeri teknik ve ihtisas okulları açtı." ifadesi durumu özetler niteliktedir. Osmanlı, modernizmin eğitim anlamında dayattı̆̆ yeniliklerle nasıl baş edeceği ve bunu nasıl firsata çevireceği anlamında Tanzimat'tan Cumhuriyet Dönemi'ne kadar askeriye haricindeki okullarda da eğitim politikaları geliştirdi. Şen'in (2013, s.484-485) ifadesiyle bu politikalar özellikle II. Abdülhamit döneminde önem kazandı, farklı statülere bölünerek çeşitlendi, Anadolu'ya yayılmaya başlandı ve Fransız eğitim sistemi örnekliğinde bugünkü modern eğitimin temelleri atıldı. Bu politikalar erken Cumhuriyet tarihine kadar sürekli değişerek uzandı. Okullarda yavaş yavaş geleneksel eğitimin yerini müfredat, öğrenim şekli (karma eğitim) vb. anlamda yeniliklerle modern eğitim almaya başladı ve erken Cumhuriyet Dönemi'nde bu doğrultuda kimilerine göre radikal kimilerine göre ise olması gereken bir şekilde politikalar üretildi. Meselenin temelinde Tevhid-i Tedrisat Kanunu yatıyordu. Bu kanunla tekke ve zaviyeler gibi geleneksel öğretim kurumları kapatılarak okulların modern eğitime geçirilip tek çatı altında toplanması istendi ve böylelikle farklı amaç ve nitelikteki tüm eğitim kurumları Maarif Vekaleti'ne bağlandı. Erken Cumhuriyet'te, eğitim politikalarında millileştirme devri (1923-1938) olarak anılan zamandan Köy Enstitüsü düşüncesinin oluşmasına kadar uzanan zaman diliminde önemli eğitim politikaları ise Tevhid-i Tedrisat'tan sonra sırasıyla; Türk Harflerinin Kabul ve Tatbiki Hakkında Kanun, İlkmektep Muallim ve Vazifeleri Hakkında Kanun, Köy Eğitmenleri Kanunu ve Köy Enstitüleri Kanunu şeklindeydi (Hesapçığlu, 2009, s.122-123). Hülasa, mevcut geleneksel eğitim kurumları Tanzimat'tan bu yana sürekli evrilerek, geliştirilmeye çalışılarak, ilk etapta muhtevasından ziyade şekil olarak değiştirilerek Cumhuriyet'e kadar gelmiştir ve burada da bugünkü sınırlar çizilmeye başlamış, kurumların bütünleştirilmesine gidilmiştir. Bunun yanı sıra modern eğitimin halka götürülmesi, yeni modern müfredatla halkın kalkındırılarak devletin muasır düzeye getirilmesi, okuma yazma oranının arttırılması düşüncelerinden de yola çıkılarak Köy Enstitüleri gibi bazı kurumların açılmasına yönelik girişimler olmuştur. 


\section{Köy Enstitüleri}

Köy Enstitüleri erken Cumhuriyet tarihinde açılmış okullar olarak hayatlarına başlamışlardır. Bu enstitülerin veya bu gibi kurum-kuruluşların geliştirilmesine, Osmanlı zamanında başlayan eğitimde modernleşme çalışmalarının devamı olarak bakılabilir. Çağın şartlarına uygun bireyler yetiştirme çabaları Cumhuriyet Dönemi’nde de iyice artmış ve belirli fikirler çerçevesinde yeni kurumlar ihdas edilmiştir. Yeni kurulan devlette, eğitime daha çok önem verilmesi gerektiğinin üzerinde durulmuş ve nüfus dağılımı da göz önüne alınarak eğitim anlamında köylere ağırlık verilmiştir. Ezer'in (2019, s.1792) “1935 yılında ülke nüfusunun yaklaşık \% 80’e yakın kısmının yaşamış olduğu kırsal kesimde okullaşma oranı yok denecek kadar azdı.” açıklamaları nüfus dağılımını ortaya koymaktadır. Ancak köye eğitim için gitmeden önce bir sorun vardı ki o da öğretmen yokluğudur. İşte tam da burada ve bu düşüncelerle Köy Enstitülerinin zemini oluşmaya başlamıştır. Köy Enstitüleri, askerliğini onbaşı veya çavuş olarak yapanların köylerine öğretmen olarak atandığı köy eğitmen kursu denemesinin başarılı görülmesinden sonra köye öğretmen yetiştirmek için 1940 yılında Maarif Vekili Hasan Ali Yücel ve İlköğretim Umum Müdürü İsmail Hakkı Tonguç liderliğinde bir eğitim projesi olarak geliştirilip başlatılmıştır. 5 yıl olan bu kurum karma eğitim vermekteydi (Bahadır, 2002, s.283). Buradaki temel felsefi görüş köyden birisinin köye öğretmen olmasıydı. Bu enstitülerin müfredatına gelindiğinde ise öğrencilerin okuma-yazma ve kültür bilgisinin yanı sıra teknik eğitimin gereği de eklenmişti. Çoban'ın (2011, s.451) "Köy Enstitüleri farklı bir eğitim anlayışı ile 'iş içinde eğitim'i uygulamaya koyan, demokratik yapı ve işleyişe sahip, eşitlikçi bir deneyimi uygulamaktaydılar." ifadesinden de teknik meselenin önemliliği anlaşılmaktadır. $\mathrm{Bu}$ bağlamda Köy Enstitülerinde "Öğrencilerin kalacağı binaların yapım ve onarım işleri öğrenciler tarafindan yapılacak, yiyecek giyecek gibi ihtiyaç maddeleri enstitünün kendi imkânları ile karşılanacaktı.” (Ezer, 2019, s.1793). Kısaca enstitünün yönetmeliğine göre amacının köye uyum sağlayacak öğretmenler yetiştirmek, eğitim yoluyla köylüleri bilinçlendirip tarımdan da verim elde etmek, Cumhuriyet değer ve duygularına sahip bir nesil yetiştirmek, okuma yazmanın yanı sıra teknik anlamda da köylünün donatılıp kalkınmasına yardımcı olmak vb. olduğu söylenebilir (Ezer, 2019, s.1797-1798). Bu şekilde planlanmış olan Köy Enstitüleri Anadolu'da belirli bir süre çoğalmıştır. Fakat kurulurken 278 milletvekilinin kabulüyle yasalaşmış olan enstitülerin durumu, 148 milletvekilinin de oylamaya katılmamasıyla sonunun çok iyi olmayacağını ve enstitülere yapılan itirazların boyutunu ortaya koyuyordu (Kafadar, 2007, s.374). Enstitülere olumlu bakıp kabul oyu veren milletvekilleri enstitülerin yeni müfredatı ve muhtevasıyla halka uyumlu olacağı, enstitüler sayesinde daha hızlı öğretmen yetiştirilebileceği ve köylerin -dolayısıyla- ülkenin eğitim anlamında hızlıca kalkınacağı düşüncesine sahiptiler. Öte yandan enstitünün yasalaşmasına ve kurulmasina olumlu bakmayıp oylamaya katılmayan milletvekilleri ise enstitülerin köyün sosyal yapısına uymayacağı, milletin hâlâ gelenekten kopamadığı vb. konusunda tepkiler vermişlerdir. Her iki görüşün de enstitülere karşı amaç bağlamında farklı bakışları olmuştur. Açılmasını olumlu gören kimseler bu kurumlarla tamamen halkın kendi içinde kendi kendini geliştirmesinin uygun olduğunu söylerlerken olumsuz 
bakanlar, asıl amacın hükümetin bu kurumlarla yeni devletin ideoloji ve kavramlarını halka dayatmak ve siyasi ideoloji empoze etmek olduğunu, enstitülerin halka şeklen uymayacağı görüşlerinin yanı sıra savunmuşlardır. Örneğin Çınar'a (2009, s.513) göre "Tek Parti döneminde merkez, Köy Enstitüleri tecrübesi hariç, kendi değerlerini yaygınlaştırmak için agresif bir kampanya izlememiştir." Başka bir görüş olarak Aktaş (2009, s.731) ise Köy Enstitülerinin bürokratik bir ödev olarak tesis edildiğini düşünmektedir. Yine bir başka örnekte ise bu görüşleri temelde desteklercesine "Geliştirilen reformlar sslahat değil ihtilal niteliğindeydi. Sosyal, siyasal ve kültürel sorunların sslahatla çözülmesinden ziyade çözüm, siyasal ve toplumsal değişmeye yönelik radikal bir hal almıştır. Gelenekten radikal anlamda ayrılmayı hedefleyen değişmenin odağında din yerine laiklik ilkesini getirmek vardı.” (Kafadar, 2007, s.351) şeklinde bir görüş vardır. Öte yandan Köy Enstitülerine olumlu bakanlardan biri olan Başaran (2010, s.25-27) ise Cumhuriyet eğitim düzeninin akılc1, karma ve çağdaş bir eğitimi gerçekleştirdiğini ve Köy Enstitüleriyle beraber tabanda bir Rönesans devinimi yaşandığını, eğer planlandığından erken kapanmasaydı on yılda köylerin öğretmen evi, dersliği, uygulama bahçesi vb. üretim birimlerine kavuşacağını, eğitimde sınıflararası eşitsizliğin ortadan kalkacağını, işkenceye dönen üniversiteye giriş sınavlarına gerek kalmayacağını ifade etmiştir. Kuruluşunun 70. Yılında Bir Toplumsal Değişim Projesi Olarak Köy Enstitüleri Sempozyumu'nun (2010) sonuç bildirgesi ise Başaran'ın (2010) görüşlerini aynı şekilde destekler niteliktedir. Özetle modern eğitim anlayışının ürünü olan Köy Enstitüleri öğretmen yetiştirmek gibi belirli amaçlarla açılmış, açılmasına destek verenler olduğu gibi asıl amacının söylenenden farklı olduğunu iddia ederek karşı çıkanlar da olmuştur. Bozkırdaki Çekirdek romanında da Kemal Tahir, Köy Enstitülerine karşı eğitim felsefesi anlamında eleştirel bir yaklaşım ortaya koymuştur.

\section{Bozkırdaki Çekirdek’te Köy Enstitülerine Bakış}

Bozkırdaki Çekirdek Kemal Tahir tarafından 1967 yılında yazılmış, özelde Köy Enstitülerini inceleyen bir köy romanıdır. Özellikle Köy Enstitülerini anlatmak için ortam, deney ve bozkırdaki çekirdek bölümleriyle meseleyi politikacılar, halk, pazar, öğrenci vb. ekseninde detaylıca işler. Tek Parti dönemindeki eğitim sürecini ve eğitim felsefesini de yer yer politik bakış açısıyla eleştirir. Açılan Köy Enstitülerine karşı farklı düşünceleri ortaya koyar ve okuyucularına tercih imkânı sunar. Bütün bunları anlatırken Köy Enstitülerinin önemine ve kapatılıp kapatılmayacağı, gerekli olup olmadığı anlamındaki tartışmalara müdür Halim Akın ve bilhassa müfettiş Şefik Ertem karakteriyle değinir. Enstitülerin eğitim felsefesi meselesini özünde bu iki karakterle işler. Şefik Ertem müfettiş olarak okulları denetleyen ve olaylara üst perdeden değişik taraflarıla bakmayı bilen birisidir, enstitülere olumlu bakmaz. Müdür Halim Akın ise Kastamonu taraflarında yapılacak olan yeni bir enstitünün müdürü olarak enstitüyü kendine ülkü edinmiş bir karakterdir. Şefik Ertem köylüyü, enstitüyü ve enstitüden öğrenci yetiştirme durumunu "bozkırdaki çekirdek" diye niteler ve normal bir çekirdeğin yeşermesi gerektiğini fakat bozkırdakinin kanununun yeşermemek olduğundan bahseder 
(Tahir, 2011, s.436). Çünkü onun gelişmesinden rahatsız olan güçlerin olduğunu ve bu güçlerin en ufak bir filizi hemen ezdiğini iddia eder. Köyün kalkınmasında kendi haline bırakılması gerektiğini ve şehirden gelenlerin köyü düzeltme girişimlerinde başarısız olacaklarını savunur. Bir başka yerde ise Şefik Ertem’in "Bozkırdaki çekirdek, yaşamasını yeşermemeye bağlamış dedik. Bozkırdaki Çekirdek, yeşerirse ya kopuyor Bozkırdan, ya da eziliyor. Böylece, Bozkırın, Bozkır kalmasına çıkıyor, sonuç... Anladınız mı, neden ciddîye almıyorum, esdüdüleri?” (Tahir, 2011, s.437) söyleminden bozkırda yetişen köylü birisinin buraya politika yapımcılarının düşündüklerinin aksine öğretmen olarak faydalı olamayacağını ve buradan gitmek isteyeceğini ya da öğretmenlerin köylülerin içinde ezileceğini, onlara yabancı kalacağını anlamak mümkündür. Şefik Ertem bu bakışıyla enstitünün amaçlandığı gibi sonuçlar doğurmadığını ortaya koymaktadır. Yine Şefik Ertem' in bir başka yerdeki ifadeleri ise bu düşünceleri tamamlar niteliktedir: "Bilmem ki ... Enstitülerde saflıkları bozulmadan yetiştirdiğimiz çocuklar, bin yıldır değişmeyen köyde ne yaparlar? Ya bizim öğretmen okullarından çıkanların ezici çoğunluğu gibi barınamazlar, savuşurlar, ya da mizaçlarına göre köy imamına döner, bazısı işini yürütüp ağa mütegallibe olur.” (Tahir, 2011, s.181). Öğretmenin köylünün içerisinde barınamayışına da romandan örnek olarak, öğretmenlerin okulların sahibi gibi düşünülüp çocuklara kendi okullarındaki eksiklerin enstitünün eğitim felsefesi gereği kendilerine yaptırıldığında, köylünün öğretmenden yaka silkip öğretmenin çocukları köle gibi çalıştırdığı iddiaları verilebilir. Bunun yanı sıra Halim Akın ise bir ülkücü olarak ideallerinin peşinde vatana hizmet aşkıyla koşar ve enstitü çalışmalarına başlar. Şefik Ertem'in işin içerik ve felsefesinde yanlış bulduğunu o 'Şefik'çiğim, öğretmen okullarınız köylere yeterince öğretmen yetiştirdi de, ENSTİTÜ belasını keyfimizden mi karşınıza çıkardık? Kestirmeden gitmek zorunda değil miyiz?” (Tahir, 2011, s.176) diyerek doğru bulur ve öğretmen eksikliğinin çok olup mevcut şartlarla köylerin nüfusuna öğretmen yetiştirilemeyeceğini ve bunun hızlandırılmış öğretmen yetiştirme projesi olduğunu ima eder. Halim Akın’ın enstitünün hızlı öğretmen yetiştirme amacına ek olarak yeni alfabenin de buna katkısı olduğu iddialarına Şefik Ertem, yeni alfabenin kabulünden bu yana 20 yıl geçtiğini ve okuma bilmeyenlerin hâlâ yüzde yetmiş oranında olduğunu, bunun nedeni olarak da köylünün okumayla işinin olmadığını iddia ederek karşıl1k verir. Lerner'in (1964, s.123) “Köy Enstitüleri yoluyla sağlanan ilerleme çok yavaştır. Pek çok kişi güçlükle okumayı öğrenebilir ama yazmayı değil. Okuma yazmayı sökebilir ama okuryazar düşünme biçimini kazanamaz. İmza atabilecek ya da vergi ilanlarını anlayabilecek kadar okuryazar olurlar ama katılımın dışında kalırlar." şeklinde ifadelerine benzer şekilde Şefik Ertem de romanda aynen katılır ve köylünün okuma yazma ile işinin olmadığına dikkat çekerek enstitünün onlara dayattığını 'yarım yırtık okutma' olarak niteler. Müdür Halim Akın her ne kadar enstitüleri savunsa da, köylüyü kültürel, sosyal ve fikri bağlamda kalkındırmaya kendini adamış bir er olarak konumlandırsa da köye ve köylüye yabancı oluşu kitapta açıktır. Ayrıca enstitüde köylü çocuklarla birlikte olduğu vakitlerde yaptığı tespitlerde de, köylülerin dünya görüşlerinin pek az değiştiğini ve değişeceğini, enstitü için çalıştıklarında kendileri için değil emir verenler için çalıştıklarını düşündüklerini ve emir verenler ortadan yok olunca kaytardıklarını söyler. Böylelikle alttan alta kendisi de köylü çocukların 
sisteme uzaklığını kaydeder. Sözgelimi bütün bu düşüncelerin sonucunda ise Şefik Ertem, Köy Enstitülerinin köylüyü eğitmek için kolaya kaçan, meseleyi anlamayan bir yap1 olduğuna, Osmanlı'dan sonra 1940'larda bile hâlâ halkın gelenekten kopamadığg, bu modern yapı ile her yönden çatışacağı kanısına varır. Köylünün ne istediğinin asıl mesele olduğunu söyler.

\section{Sonuç}

Eğitim, insan var oldukça var olmaya devam edecektir. Modernizmin eğitim anlamındaki getirileri de hiç şüphesiz tartışılmaya devam edecektir. Modern eğitimin Osmanlı'dan bu yana getirdiği yenilikler Cumhuriyet Dönemi'nde de devam etmiş, birçok yeni kanunlar tasarlanmış, özellikle Cumhuriyet’ten sonra köylerde eğitime önem verildiğinden dolayı Köy Enstitüleri gibi kurumlar açılmıştır. Bu enstitülerin öğretmen sayısının arttırılmasına katkı sağladığı, bu sayede nüfusu fazla olan köylü halkın öğretmene kavuşup hızla gelişmesiyle ülkenin hızlı kalkınacağı, okuma yazma sayısının artacağı, köylünün kendi kendine yeteceği gibi görüşlerin yanı sıra; geleneksel değerlere olan uyumsuzluğu, köylülerin habitatına uymadığı ya da politik amaçlara hizmet ettiği gibi düşünceler de öne sürülmüştür. Kemal Tahir de Bozkırdaki Çekirdek romanıyla bu olayları derlemiş ve her boyutuyla işlemiştir. Romanda özellikle de eğitim modeli olarak karşımızda duran Köy Enstitüsünün maddi katkılarını veya maddi kaygılarla enstitünün yararlı olacağı düşüncesini, bu enstitülerin felsefi arka planını ve işin düşünsel kısmında yanlışlıkların olduğunu öne sürererek eleştirmiştir. Meselenin yeniden düşünülmesi gerektiğini iddia etmiş ve özellikle Şefik Ertem karakteriyle sistemde gördüğü yanlışlıkları eğitim felsefesi açısından ele almıştır.

\section{Kaynakça}

Aktaş, Ü. (2009). "Türkiye siyasetinin muhalif iki akımı islamcılık ve sosyalizm”. Modern Türkiye'de Siyasi Düşünce içinde (Cilt 9, s.722-757). İstanbul: İletişim Yayınları.

Bahadır, Z. (2002). “Köy ensitüsü”. TDV İslam Ansiklopedisi içinde (Cilt 26, s.283-285). Ankara: Türkiye Diyanet Vakfi.

Başaran, M. (2010). "Eğitim yaşama hakkıyla özdeş bir hak”. Kastamonu Üniversitesi Dergisi, 9, 24-29.

Beriş, H. E. (2003), “Moderniteden postmoderniteye”. Mümtaz’er Tüköne (Ed.), Siyaset içinde (s.485-496). Ankara: Lotus Yayınevi.

Bozaslan, B. M. ve Çokoğullar, E. (2015). “Osmanlı'dan Cumhuriyet'e modern eğitimin inşası: devletin kurtarılmasından devletin kurulmasına”. Gazi Üniversitesi İktisadi ve İdari Bilimler Fakültesi Dergisi, 17(3), 309-329.

Çınar, M. (2009). “Merkezsiz siyaset, siyasetsiz merkez”. Modern Türkiye’de Siyasi Düşünce içinde (Cilt 9, s.479-518). İstanbul: İletişim Yayınları.

Çoban, A. (2011). "Öğretmen yetiştirme politikası olarak köy enstitüleri örneğinin incelenmesi”. Kastamonu Eğitim Dergisi, 19(2), 449-458. 
Ezer, F. (2019, Yaz). “Köy enstitülerinin Türk eğitim tarihindeki yeri ve önemi”. Belgi Dergisi, 2(19), 1786-1804.

Hesapçığlu, M. (2009). “Türkiye'de cumhuriyet döneminde eğitim politikası ve felsefesi”. M.Ü. Atatürk Eğitim Fakültesi Eğitim Bilimleri Dergisi, 29(29), 121-138.

Kafadar, O. (2007). “Cumhuriyet dönemi eğitim tartışmaları”. Modern Türkiye'de Siyasi Düşünce içinde (Cilt 3, s.351-381). İstanbul: İletişim Yayınları.

Kuruluşunun 70. yılında bir toplumsal değişim projesi olarak köy enstitüleri sempozyumu sonuç bildirgesi”. (2010). Kastamonu Üniversitesi Dergisi, 9, 9.

Lerner, D. (1964). The Passing of Traditional Society: Modernising the Middle East. New York: The Free Press Glencoe, Collier-Macmillan.

Şen, A. (2013). “Osmanlı'dan günümüze eğitimde modernleşme çabaları”. Ekev Akademi Dergisi, 17(57), 477-492.

Tahir, K. (2011). Bozkırdaki Çekirdek. İstanbul: İthaki Yayınları. 
